\title{
Evolución de la auditoría de gestión
}

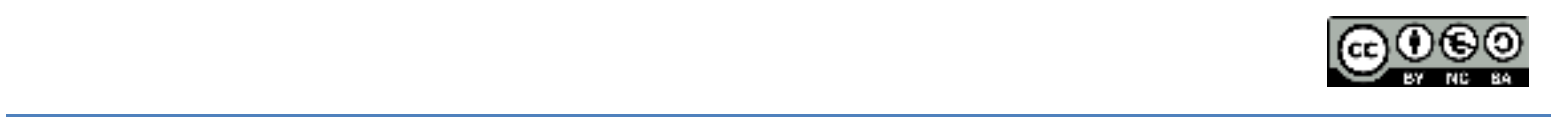

Evolución de la auditoría de gestión

Rosa Verónica Núñez Liberio. MIAGE. ${ }^{1}$, Proaño Gonzales Esther Angélica. MAE. ${ }^{2}$ \& Leici Edid Quiñónez Cabeza MAE. $^{3}$

\begin{abstract}
.
DOI: $\underline{\text { https://doi.org/10.33262/cienciadigital.v2i1.26 }}$

Achieving success in the administration of an organization does not depend exclusively on an adequate management system but on the good repute, good conduct and transparency of the people who execute it, as well as an adequate supervision model on a permanent basis. Through an inclusive methodology of content analysis that involved auditors and auditors, this investigation warns that the internal control and audit system is contaminated, which determined as the main problem the collection of information and the documentation of the processes carried out. The results showed that the majority of audit processes comply with the established theoretical formats, but do not evaluate or sanction with the same criteria. That is to say tha when organizations or people with political or influential power are involved in society, then the evaluation of administrative processes becomes a simple report of compliance with processes and not the achievement of objectives according to a legally approved plan. Contrary to what was believed, transparency is often less important, both for the auditee and for those who exercise control.
\end{abstract}

Keywords: Law Enforcement, Economic Behavior, Management Audit, Government Control, Corruption.

\section{Resumen.}

Alcanzar el éxito en la administración de una organización no depende exclusivamente de un adecuado sistema de gestión sino de la honorabilidad, la buena conducta y la transparencia de las personas que lo ejecutan, así como de un adecuado modelo de supervisión de forma permanente. Mediante una metodología

\footnotetext{
${ }^{1}$ Universidad Técnica Luis Vargas Torres de Esmeraldas Ext. la Concordia, rosa.nunez@utelvt.edu.ec ${ }^{2}$ Universidad Técnica Luis Vargas Torres de Esmeraldas Ext. la Concordia, esther.proano@utelvt.edu.ec ${ }^{3}$ Universidad Técnica Luis Vargas Torres de Esmeraldas Ext. la Concordia, leici.quinonez@utelvt.edu.ec
} 
inclusiva de análisis de contenido que involucró a auditores y auditados esta investigación advierte que el sistema de control interno y de auditoría está contaminado, lo que determinó como principal problema la recopilación de información y la documentación de los procesos realizados. Los resultados mostraron que la mayoría de procesos de auditoría cumplen los formatos teóricos establecidos, pero no evalúan ni sancionan con el mismo criterio. Es decir que cuando se encuentran involucradas organizaciones o personas con poder político o influyente en la sociedad, entonces la evaluación de los procesos administrativos se convierte en un simple informe de cumplimiento de procesos y no de consecución de objetivos acordes a una planificación legalmente aprobada. En contra de lo que se creía, muchas veces la transparencia es menos importante, tanto para el auditado como para quien ejerce el control.

Palabras Claves: Aplicación de la ley, comportamiento económico, auditoría de gestión, control gubernamental, corrupción

\section{Introducción.}

La auditoría pretende establecer una opinión de los procedimientos utilizados durante la administración, con énfasis en la razonabilidad de los recursos financieros, de ésta manera la auditoría procura ayudar a los administradores a incrementar su rendimiento mediante recomendaciones, utilizando los informes financieros como un medio para alcanzar la eficiencia de su gestión, estableciendo recomendaciones que permitan el incremento de los ingresos, la reducción de los costos, la simplificación de tareas, la aplicación permanente de las disposiciones legales (Florian , 2016)

Originalmente la auditoría procuró satisfacer necesidades internas de las instituciones como el manejo seguro del dinero y el registro oportuno de las operaciones, la complejidad estructural de las organizaciones obligó a que la auditoría se oriente hacia la necesidad de garantizar el registro correcto de los procesos ejecutados, en los cuales podían confiar los ejecutivos y dueños del negocio. Esta necesidad adicionalmente obligó a que los procesos de auditoría se especialicen dependiendo de su aplicación, es así que se fue consolidando la auditoría de gestión, auditoría financiera, auditoría ambiental, auditoría gubernamental entre las principales (Freire, 2011).

La auditoría gubernamental se origina con la necesidad de determinar la legalidad de las transacciones y la seguridad en el manejo de los recursos públicos que se encuentran administrados no solo por el Estado sino además por quienes reciben pagos y contribuciones de él, utilizados por organizaciones o por contratistas que ejecutan obra pública. El objetivo final de la investigación es establecer la importancia de la auditoría de gestión y contribuir con el perfeccionamiento de los procesos utilizados para su ejecución; 
y, demostrar que la legislación actual contiene vacíos que eventualmente permiten posibles actos de corrupción se presenten no solo en los ejecutores de los procesos sino en quienes los auditan, considerando que la corrupción también es omitir la investigación de determinados procesos así como despreocuparse de la obligación de exigir el cumplimiento de las recomendaciones establecidas en los informes finales de auditaría; y principalmente demostrar la importancia que tiene la auditoría de gestión en la consecución de los objetivos establecidos en la planificación institucional (Marques , 2001).

\section{Materiales y métodos.}

Para el estudio de la aplicación de una auditoría de gestión se empleó el método de análisis de contenido, lo que permitió reconocer el significado de los elementos que contenían los documentos analizados mediante criterios objetivos y sistemáticos debido a que fue preciso la sujeción del análisis a una pauta objetiva determinada incluyendo todo el contenido analizado. Esta técnica tuvo la característica de manifiesto ya que se observaron los contenidos expresos de comunicaciones oficiales y definitivas. Una vez que se determinó la fuente de donde se obtuvieron las muestras, se estableció el periodo del cual se las tomaría, en nuestra investigación se decidió tomar como fuente la Contraloría General del Estado de la República del Ecuador, el tamaño de la muestra fue de 20 auditorías concluidas y archivadas, en el periodo comprendido entre el 2008 y 2017, periodo en el cual existieron cambios significativos en toda la legislación ecuatoriana, cambios que se producen a partir del 2009 incluida una nueva Constitución, una nueva Ley Orgánica de la Contraloría General del Estado y nuevas normas de Control Interno, de esta manera se pudo observar auditorías realizadas con dos legislaciones diferentes. Una vez analizados los documentos se contactó a varios auditados y auditores implicados en los procesos de análisis de contenido, lo que permitió entender el porqué de las inconsistencias en los resultados presentados en dichos informes. En la investigación, además se analizó la legislación que debió observarse en los procesos auditados y en la auditoria ejecutada para cada caso.

\section{Análisis de resultados.}

Mediante las entrevistas realizadas a los auditores y a los auditados se obtuvieron como resultados que todos los casos investigados inicialmente se relacionan con la estructura del informe detectando que son impecables, es decir, que el equipo de auditoria implicado cumplió correctamente con la aplicación de las Normas de Auditoria vigentes, sin embargo, las recomendaciones a los auditados de diferentes organizaciones que incumplieron los mismos procesos, no recibieron las mismas sanciones. 
Un segundo resultado de la investigación demuestra el incumplimiento de las recomendaciones del equipo de auditoría ya que no sancionaron en todos los casos, pero cuando lo hicieron, no siempre fueron las mismas sanciones. Otro resultado de la investigación detectó que las justificaciones aceptadas y/o rechazadas por el equipo de auditoría en exámenes especiales idénticos, en algunos casos son aceptadas y las mismas en otros casos son rechazadas.

Un resultado final determinó que los equipos de auditoría autorizados por el ente rector que desempeñan sus funciones en diferentes instituciones, que a pesar de estar integrados por especialistas en diferentes ramas, son autorizados para ejecutar el mismo tipo de auditoría, por ejemplo, un auditor que no es informático realiza auditorias informáticas, sin que exista el registro de un especialista en ese campo. Otras investigaciones demuestran que la falta de integridad en los procesos de auditoría está relacionada con los riesgos de auditoría, puesto que, el análisis de riesgos constituye una herramienta indispensable para el cumplimiento adecuado del equipo auditor:

Los profundos cambios que ocurren hoy, su complejidad y la velocidad con los que se dan, son las raíces de la incertidumbre y el riesgo que las organizaciones confrontan. Las fusiones, la competencia global y los avances tecnológicos, las desregulaciones, y las nuevas regulaciones, el incremento en la demanda de los consumidores y de los habitantes, la responsabilidad social y ambiental de las organizaciones así como, la transparencia generan un ambiente operativo, cada día más riesgoso y complicado, surgiendo en adición nuevos retos con los cuales lidiar, resultado de los problemas que se presentan en las organizaciones que operan al margen de la ley o de conductas éticas.

\section{Discusión.}

Los resultados obtenidos demuestran que un sistema administrativo público o privado permanentemente está tentado por intereses de enriquecimiento o por mecanismos de elución de responsabilidades, sanciones o penas, se deben principalmente a la falta de aplicabilidad de la normativa legal vigente en las instituciones, así como a la falta de ética de funcionarios, directivos y autoridades. Por otra parte las debilidades de la auditoría han impedido que tenga un papel más activo en la detección de escándalos de corrupción. En ocasiones una mala y arbitraria aplicación de las normas contables han pasado por alto situaciones irregulares.

La negligencia y la falta de ética profesional es una batalla en el aumento de los intereses privados sobre los públicos, durante la investigación de algunos casos, pude determinar que varias auditorías mal realizadas se justifican por falta de experiencia en los negocios evaluados o por el desconocimiento en el manejo de sistemas complejos o por grandes volúmenes de información que se manejan. 
También preocupa el escepticismo y cautela profesional injustificada en la detección de fraude manipulando criterios de valoración contable, así como el fracaso colectivo de los sistemas de control al no anticipar las señales de alerta en la ocurrencia de fraude y al considerárseles facilitadores de estas prácticas, por lo expuesto y considerando que el conocimiento profundo de la legalidad de sus procesos administrativos y de los controles implementados para su correcto funcionamiento, considero que la auditoria es la mejor herramienta de evaluación de la gestión institucional, en este sentido considero que resulta importante investigar la evolución de la normativa con especial atención en aquellas entidades que forman parte del sector público.

Normalmente son los organismos de control del sector público los que procuran introducir normas y prácticas, tanto de origen nacional como internacional, que mejore los mecanismos de control interno, evaluación del sistema de gestión de riesgos y revisión independiente de las actividades institucionales, con el propósito de generar transparencia, confianza y adecuada información para preservar los recursos disponibles.

Una investigación sobre la evolución de la normativa aplicable en las actividades de auditoría permitirá conocer la eficiencia de los modelos de control y podría aportar un cuadro de situación con respecto a su estado actual en relación al pasado reciente y a los logros de otros países.

Para entender correctamente los resultados obtenidos es preciso comprender con claridad desde la definición misma de lo que es la auditoría de gestión así como la evolución de la normativa aplicable en estos procesos y su importancia en las políticas incluso del Estado.

Con el continuo perfeccionamiento de los procesos de auditoría de gestión, su definición igualmente va modificándose con el propósito de sintetizar en un solo concepto su propósito, alcance y el beneficio de su aplicación, es así que, para establecer la más adecuada definición mencionaremos algunas definiciones propuestas por varios autores e instituciones destacadas.

En el Ecuador la rectoría del sistema de control del sector público le corresponde a la Contraloría General del Estado, organismo que define el control de la gestión como:

Un examen de la economía, efectividad y eficiencia de las entidades de la administración en el ejercicio y protección de los recursos públicos, realizado mediante la evaluación de los procesos administrativos, la utilización de indicadores de rentabilidad pública y desempeño y la identidad de la distribución del excedente que éstas producen, así como de los beneficios de su actividad (Contraloria General Del Estado, 2014).

La Contraloría General de los Estados Unidos de América (GAO, 2011), define la auditoría como: 
Examen objetivo y sistemático de evidencias con el fin de proporcionar una evaluación independiente del desempeño de una organización, programa, actividad o función gubernamental que tenga por objetivo mejorar la responsabilidad ante el público y facilitar el proceso de toma de decisiones por parte de los responsables de supervisar o iniciar acciones correctivas. La auditoría operativa abarca la economía y eficiencia y la auditoría de los programas. Dan énfasis a la medida de la calidad de los productos y servicios gubernamentales, comparten la opinión de que los funcionarios gubernamentales deben dar seguridad a los contribuyentes de que los fondos públicos son utilizados con criterios de: economía, eficiencia y eficacia (Contraloria, 2001)

"Una auditoría de gestión consiste en un examen independiente, objetivo y fiable de si las iniciativas, sistemas, operaciones, programas, actividades u organizaciones funcionan con arreglos a los principios de economía, eficiencia y eficacia, y si existe margen de mejora" (Tribunal de cuentas europeo, 2015)

También se define a la auditoría como:

Un examen independiente con el fin de proveer a la legislatura una evaluación e informe sobre la marcha en que los administradores de las entidades y dependencias del Estado han descargado sus responsabilidades de administrar los programas del Estado de manera fiel, eficiente y efectiva. (Tribunal de cuentas europeo, 2015)

Una definición destacada establece que es:

El control gubernamental consiste en la supervisión, vigilancia y verificación de los actos y resultados de la gestión pública, en atención al grado de eficiencia, eficacia, transparencia y economía en el uso y destino de los recursos y bienes del Estado, así como del cumplimiento de las normas legales y de los lineamientos de política y planes de acción, evaluando los sistemas de administración, gerencia y control, con fines de su mejoramiento a través de la adopción de acciones preventivas y correctivas pertinentes. El control gubernamental es interno y externo y su desarrollo constituye un proceso integral y permanente (Contraloria, 2001)

La Auditoría es la evaluación multidisciplinaria, independiente, con enfoque de sistemas, del grado y forma de cumplimiento de los objetivos de una organización, de las relaciones con su entorno, así como de sus operaciones, con el objeto de proponer alternativas para el logro más adecuado de sus fines y/o mejor aprovechamiento de sus recursos. Induce a una reflexión sustantiva sobre el plan estratégico de una dependencia o entidad pública y orienta la toma de decisiones hacia el cabal cumplimiento de los objetivos que demanda la sociedad, la función preventiva de la auditoría permite identificar a tiempo: los errores humanos, contables, financieros y la desviación de objetivos o funciones institucionales; el incumplimiento, retraso o falta de interés en las tareas y responsabilidades y en las 
necesidades de información a titulares de los entes para la toma de decisiones Academia Mexicana de Auditoría Integral (Florian , 2016)

Considerando las definiciones anteriores podríamos concluir diciendo que la auditoría de gestión es una herramienta que procura optimizar los procesos de una organización orientando su gestión hacia la producción de mejores rendimientos, mediante técnicas de asesoramiento permanentes que permitan analizar, diagnosticar y establecer recomendaciones con el fin de conseguir con éxito una adecuada estrategia de producción, a través, de un examen especial que evalúa el grado de eficiencia y eficacia con que se manejan los recursos disponibles cuyo propósito debe ser el alcanzar los objetivos de la organización, apoyándose en información estadística, financiera, administrativa y operativa. La auditoría de gestión cuando determina irregularidades en procesos específicos de la organización recomendará exámenes especiales dirigidos a evaluarlos de forma puntual, a través, de auditorías financieras, informáticas, ambientales (Rodriguez, 2015).

\section{Cronología de la normativa más relevante en la evolución de la auditoría de gestión.}

En el Ecuador a lo largo de su historia se han implementado varias normas de uso obligatorio en los procesos de auditoría, especialmente en el sector público como parte de un proceso constante de lucha contra la corrupción, observando experiencias pasadas tanto nacionales como internacionales, adicionalmente en los procesos de auditoría también se observan las publicaciones de la Federación Internacional de Contadores (IFAC).

En el proceso de mejorar la normativa de auditoría de gestión se han observado otras disposiciones internacionales tales como las NIC y NIIF. La historia del inicio de la auditoría en el Ecuador se encuentra publicado en el portal de la Contraloría General del Estado, de donde se tomó la siguiente reseña:

Ya en los siglos XVI, XVII, XVIII y principios del XIX en la Real Audiencia de Quito, se implementaron organismos de control conocidos como Contadurías Mayores; y, en la Gran Colombia, a partir de 1822 se fundó la Contaduría General de Hacienda; posteriormente en 1824 se suprime la Contaduría General y se crean las Contadurías Departamentales en Quito, Guayaquil y Cuenca; en 1826 se restablece la Contaduría General y se crean los puestos de Contadores Generales y Contadores Departamentales. Como República, en 1830 se establece la Contaduría General y la Contadurías Departamentales; en 1846 se instituyen las Contadurías Mayores por cada una de las ciudades de Quito, Cuenca y Guayaquil; en 1851 se establece la Contaduría General como un Tribunal Superior de Cuentas y las Contadurías Mayores como juzgados de Distrito; en 1861 se crea el Tribunal de Cuentas y en 1896 se crea el Tribunal de Cuentas de Guayaquil.

El 2 de diciembre de 1927, como consecuencia del asesoramiento prestado al país, por la Misión Kemmerer, entró en vigencia la Ley Orgánica de Hacienda, publicada en el 
Registro Oficial No 448 de 16 de noviembre de 1927, que crea la Contraloría General de la Nación, como departamento independiente del gobierno, con el objeto de realizar el control fiscal, compilar cuentas y constituir la oficina central de la Contabilidad del Estado.

Con el Decreto Ley 1065-A se reforma a la ley Orgánica de Hacienda de 1927; tales enmiendas son codificadas en 1960, estableciendo que la Contraloría debe tener un sistema moderno de control (Sistema Integrado de Administración Financiera y Control) con el fin de precautelar la economía, efectiva y eficiente administración de los recursos humanos, materiales y financieros, para controlar oportunamente los fondos fiscales y satisfacer las necesidades del servicio público y del desarrollo del país; en 1956 se expide el "Nuevo Reglamento" que establece la estructura organizacional de la Contraloría que contempla una división de 10 departamentos a cargo de un Director (Neira , 2015).

En la Constitución de 1967 se le asignaron, además, funciones de fiscalización y se cambió la denominación de Contraloría General de la Nación por la de Contraloría General del Estado.

En 1977 se expide la ley Orgánica de Administración Financiera y Control (LOAFYC) publicada en el Registro Oficial ·337, de 16 de mayo de ese año, con la cual se sustituyó a la Ley Orgánica de Hacienda Codificada. La LOAFYC, contiene las normas fundamentales que rigen la estructura y funcionamiento de la Contraloría General del Estado; en ella se plasmó el cambio de esta Institución dejando atrás el sistema del simple Control Fiscal para instaurar el sistema de Control Gubernamental Moderno de los recursos públicos.

Al cambiar la estructura legal y administrativa de la Contraloría, dejo de ser la oficina de Contabilidad e Intervención Fiscal, se constituyó como un Organismo Superior de Control de los recursos de las entidades del sector público. Este control lo efectuará mediante un examen posterior a las operaciones financieras y administrativas de cada entidad a través de exámenes especiales, auditorías financieras y auditorías operacionales.

Mediante Acuerdo No. 017-CG, publicado en el Registro Oficial 430 de 28 de abril de 1994, se expidieron las Normas Técnicas de Control Interno para el Sector Público de la República del Ecuador, las cuales constituyen guías generales emitidas por la Contraloría General del Estado, orientadas a promover una adecuada administración de los recursos públicos y a determinar el correcto funcionamiento administrativo de las entidades y organismos del sector público ecuatoriano, con el objeto de buscar la efectividad, eficiencia y economía en la gestión institucional. Se instrumentan mediante procedimientos encaminados a proporcionar una seguridad razonable, para que las entidades puedan lograr los objetivos específicos que se trazaron; tienen soporte técnico en principios administrativos, disposiciones legales y normativa técnica pertinente.

El 12 de junio del 2002, se publica en el suplemento del Registro Oficial N.-595, LEY N.2002-73 la Ley Orgánica de la Contraloría General del Estado; y el 10 de octubre de 2002 
mediante acuerdo $\mathrm{N}^{\circ}$ 020- $\mathrm{CG}$ en edición especial $\mathrm{N}^{\circ} 6$ se pública en el Registro Oficial reformas a las Normas de Control Interno, las cuales reciben sus últimas actualizaciones en el 2009 y 2014 por parte de la Asamblea Constituyente.

Con acuerdo No. 019-CG de 5 de septiembre de 2002 se publican las Normas ecuatorianas de auditoría gubernamental; el 8 de mayo de 2015 mediante acuerdo 17-CG de 2015 se emiten reformas al reglamento de elaboración de informes de auditoría.

Mediante acuerdo No. 024-CG de 3 de agosto de 2015 se emiten actualizaciones a las normas de auditoría gubernamental y a los manuales general y financiero de auditoría gubernamental.

En junio de 2016 se emite la nueva Normativa de Contabilidad Gubernamental.

\section{Análisis de la normativa vigente referida a normas de auditoría y control interno.}

Si considerando que la auditoría de gestión consiste en realizar un examen a todas las actividades que realizan las instituciones de forma independiente o en conjunto con otras instituciones o con algunos niveles de gobierno, entonces se debe reglamentar la forma como se la debe ejecutar para garantizar el debido proceso.

La normativa vigente disponible para la ejecución de procesos de auditoría de gestión en el sector público ecuatoriano, es muy amplia, inicialmente el procedimiento de cómo debe ejecutarse una auditoría de gestión está dispuesto por el ente rector del sistema de control, es decir, por la Contraloría General del Estado, a través, de la Ley de La CGE, normas de control interno, normas de auditoría, manuales general y financiero de auditoría gubernamental. Adicionalmente a esta normativa, deberá observarse los lineamientos legales dependiendo de la institución y de las actividades que se auditaran, tomando en cuenta, además que la mayoría de las leyes orgánicas y códigos tienen su propio reglamento y existen decretos presidenciales y acuerdos ministeriales con diferentes niveles de aplicación.

Los procesos que forman parte de la gestión son muy diversos, por ello es de vital importancia el conocimiento de la normativa vigente, pues un mismo proceso con seguridad será auditado al amparo de varias normas como por ejemplo, el proceso de administración del talento humano, deberá auditarse en función de las disposiciones de las Normas de Control Interno, el Código de Trabajo, la Ley Orgánica del Servicio Público y su Reglamento; los procesos de adquisiciones, financiero, contable y de tesorería deben auditarse observando las disposiciones de las Normas de Control Interno, la Ley Orgánica del Sistema Nacional de Contratación Pública y su Reglamento, Reglamento de administración de bienes del sector público, ley de la Economía Popular y Solidaria, Ley del Artesano, normativa dispuesta por el Servicio de Rentas Internas, normativa de 
contabilidad gubernamental, Código Orgánico de Planificación y Finanzas Públicas y su Reglamento, Plan del Buen Vivir entre otros (SEMPLADES, 2017).

Se puede entender que la auditoría de gestión implica el conocimiento de una variada y muy amplia legislación, pues en el país, a más de la constitución, existen más de cien leyes, códigos y reglamentos; así como una interminable lista de resoluciones, decretos, acuerdos, manuales, reglamentos, interfaces informáticas con sus propios manuales y funcionalidades.

Sin duda, la auditoría de gestión constituye una herramienta imprescindible que permite garantizar procesos efectivos, eficientes, éticos y transparentes, con el propósito de identificar posibles focos de corrupción que pueden ser erradicados y sancionados; en el Ecuador, a pesar del esfuerzo de emitir una normativa ágil, vemos que para los asambleístas constituye un indicador de eficiencia, es decir, que mientras más leyes se emitan mayor será su capacidad de legislar. Sin embargo, en la práctica vemos que para la ejecución de un determinado proceso, el servidor público a cargo, debe tener en cuenta mucha normativa, que en ocasiones dificulta cumplir lo dispuesto en otra norma de igual jerarquía.

Una de las principales normas que debe observarse su cumplimiento, en todas las actividades que se realizan en los diferentes procesos de la gestión institucional, son las Normas de Control Interno de la Contraloría General del Estado.

\section{Importancia de la correcta aplicación del control interno.}

El control interno es responsabilidad de cada institución conforme a su propia normativa, por lo tanto es frecuente encontrar procesos que no son permitidos en algunas instituciones $\mathrm{y}$ en otras si, de igual manera algunos procesos se permiten en el sector privado y en instituciones del Estado no se admiten y viceversa.

Las Normas de Control Interno dispuestas por la Contraloría General del Estado definen el control interno como un proceso integral aplicado por la máxima autoridad, la dirección y el personal de cada entidad, que proporciona seguridad razonable para el logro de los objetivos institucionales y la protección de los recursos. Constituyen componentes del control interno el ambiente de control, la evaluación de riesgos, las actividades de control, los sistemas de información y comunicación; y el seguimiento. El control interno está orientado a cumplir con el ordenamiento jurídico, técnico y administrativo, promover eficiencia y eficacia de las operaciones de la entidad y garantizar la confiabilidad y oportunidad de la información, así como la adopción de medidas oportunas para corregir las deficiencias de control.

El diseño, establecimiento, mantenimiento, funcionamiento, perfeccionamiento, y evaluación del control interno es responsabilidad de la máxima autoridad, de los directivos 
y demás servidoras y servidores de la entidad, de acuerdo con sus competencias. Los directivos, en el cumplimiento de su responsabilidad, pondrán especial cuidado en áreas de mayor importancia por su materialidad y por el riesgo e impacto en la consecución de los fines institucionales. Las servidoras y servidores de la entidad son responsables de realizar las acciones y atender los requerimientos para el diseño, implantación, operación y fortalecimiento de los componentes del control interno de manera oportuna, sustentados en la normativa legal y técnica vigente y con el apoyo de la auditoría interna como ente asesor y de consulta.

El cumplimiento de las Normas de Control Interno, optimiza el sistema de información, contabilidad y control, velando por la correcta aplicación de los procedimientos operativos, contables y de control interno correspondientes a las transacciones significativas desarrolladas por la entidad; la evaluación de dichos procedimientos permite determinar si son suficientes para alcanzar los objetivos de control interno correspondiente y asegurar un adecuado registro contable de las transacciones efectuadas, dando cumplimiento de los procedimientos de control interno verificando si operan adecuadamente en la práctica y permiten alcanzar los objetivos correspondientes.

\section{Normas ecuatorianas de auditoría gubernamental.}

La Contraloría General del Estado, ejerce el control de los recursos públicos descritos en el artículo 3 de su Ley Orgánica, donde se define como tales a todos los bienes, fondos, títulos, acciones, participaciones, activos, rentas, utilidades, excedentes, subvenciones y todos los derechos que pertenecen al Estado y a sus instituciones, sea cual fuere la fuente de la que procedan, inclusive los provenientes de préstamos, donaciones y entregas que a cualquier otro título realicen a favor del Estado o de sus instituciones, personas naturales o jurídicas u organismos nacionales o internacionales mediante el ejercicio de la auditoría gubernamental y el examen especial, utilizando normas nacionales e internacionales y técnicas de auditoría.

La auditoría gubernamental externa es ejercida por auditores de la Contraloría General del Estado y de las firmas privadas de auditoría contratadas por requerimiento de convenios o contratos internacionales, o por no disponer de personal especializada en determinadas áreas. La auditoría gubernamental interna, es ejercida exclusivamente por la Unidad de Auditoría Interna de cada entidad u organismo del sector público.

La finalidad básica de la auditoría gubernamental es brindar confiabilidad a la información elaborada por la administración de la entidad y determinar el grado de cumplimiento de los objetivos y metas institucionales, a fin de promover la toma de decisiones adecuadas, esto implica el cumplimiento de objetivos generales como: 
1. Evaluar la correcta utilización de los recursos públicos, verificando el cumplimiento de las disposiciones legales y reglamentarias.

2. Determinar si la gestión de los funcionarios públicos fue realizada con criterios de efectividad, eficiencia y economía y los resultados obtenidos guarde relación con los recursos asignados, de acuerdo con los planes y programas aprobados por la entidad auditada.

3. Dictaminar los estados financieros y establecer si la información elaborada por la entidad es correcta, confiable y oportuna.

Fortalecer el sistema de control interno de la entidad auditada.

Recomendar medidas para promover mejoras en la gestión pública.

Los auditores de la Contraloría General del Estado, de las Unidades de Auditoría Interna de las entidades del sector público y de las firmas privadas contratadas, llevarán a cabo los controles manteniendo independencia de criterio en las evaluaciones que ejecuten. Las actuaciones de otras unidades administrativas o instituciones del Estado, como el caso del Ministerio de Economía y Finanzas, en lo que respecta a la evaluación de la ejecución presupuestaria, no serán tomadas como sustitución de la auditoría gubernamental. Los resultados de estos trabajos constituirán elementos de juicio para la ejecución de la auditoría gubernamental.

La normativa que rige el desarrollo de la auditoría gubernamental en el sector público se encuentra dada por las Normas Ecuatoriana de Auditoría Gubernamental (NEAG) emitidas por la Contraloría General del Estado, las mismas que se fundamentan en las Normas Auditoría Generalmente Aceptadas (NAGA) y las Normas Ecuatorianas de Auditoría (NEA), que son de aplicación y cumplimiento obligatorio por parte de los auditores de la Contraloría General del Estado. Los auditores internos de las entidades públicas y los profesionales de las firmas privadas contratados de auditoría, cuando sean designados o contratados por el Organismo Técnico Superior de Control para efectuar la auditoría gubernamental.

En aquellos aspectos que no se contemplen en las Normas Ecuatorianas de Auditoría Gubernamental (NEAG) y que guarden relación con la gestión pública, será responsabilidad de los auditores gubernamentales observar las disposiciones de las Normas de Auditoría Generalmente Aceptadas (NAGA) y de las Normas Ecuatorianas de Auditoría (NEA).

Las Normas Ecuatoriana de Auditoría Gubernamental, se encuentran estructuradas de la siguiente manera: I. Relacionadas con el Auditor Gubernamental, (A.G) II. Relacionadas con la Planificación de la Auditoría Gubernamental, (P.A.C) III. Relativas con la Ejecución de la Auditoría Gubernamental, (E.A.G) y IV. Normas relativas al Informe de la Auditoría Gubernamental (I.A.G). 
La implementación de estas normas permite proporcionar evidencia directa sobre la validez de las transacciones y los saldos incluidos en los registros contables. Con referencia a los procedimientos sustantivos más relevantes se destacan los usuales en cualquier auditoría de estados contables, además se establecen la realización de pruebas sustantivas específicas de los diferentes procesos operativos.

\section{Impacto de las políticas estatales sobre los procesos de auditoría.}

No es extraño que la fuerza política de un país, siempre ejercerá presión sobre el poder legislativo en su deber independiente de proponer leyes en beneficio del soberano, el pueblo, quien depositó su confianza, esperanzado en un poder legislativo que fiscalice las tareas del ejecutivo y de los demás componentes del Estado y no al revés, como sucedió en el año 2015, cuando fue el ejecutivo, quién propuso un cambio en la Constitución de la República del Ecuador, eliminado de la Contraloría General del Estado, su facultad de realizar una auditoría de gestión en las instituciones públicas.

Con este cambio fundamental, la Contraloría General del Estado, perdió completamente su razón de control, ya que, en la actualidad, sus auditores se han convertido en unos simples analistas del cumplimiento fundamentalista de procesos, es decir, si la gestión institucional finalmente cumple con la consecución de sus objetivos, hoy es suficiente con el cumplimiento de los procesos, paso a paso, tal como han sido reglamentado.

Es indispensable establecer un mecanismo de actualización de los procesos de control, no es racional que quienes sean auditados propongan el mecanismo y las reglas que los evaluaran, esta realidad, que parecería ser el tema del peor de los filmes cómicos que se hayan producido en toda la historia de la humanidad, debe eliminarse; es indispensable entregar a la unidad de control nuevamente su rol de poder evaluar la gestión total de la administración pública; si esto parece una broma, que pensar entonces que sea el ejecutivo, quien proponga la máxima autoridad de algunas dependencias de control.

América latina y especialmente el Ecuador, en la última década ha sufrido una transformación positiva, no solamente en su modelo de administración pública, sino también en su desarrollo económico y actualmente es un referente en varios aspectos, al contar con los indicadores más sobresalientes entre los países de la región e incluso superando en algunos aspectos a otros paisas de latitudes diferentes; sin embargo, también somos referentes de actos de corrupción tanto nacionales como internacionales, probablemente por la falta de autonomía absoluta entre los entes de control y el Estado. Todos conocemos los resultados de varios procesos de auditorías de gestión o exámenes especiales, como los denomina la CGE, que han permitido desenmascarar a personajes públicos como alcaldes, ministros, secretarios de estado, asambleístas y muchos 
funcionarios públicos alineados al gobierno de turno, pero extrañamente casi en su totalidad han salido impunes, otros han fugado y unos cuantos pagan ridículas sanciones.

Como podemos apreciar, la auditoría de gestión sin duda que permite poner en evidencia los procesos que se ejecutan en la administración pública y privada, esta actividad debe apreciarse como un mecanismo que mejora la gestión y permite implementar indicadores que nos alerten de posible desviaciones que obliguen al administrador a estructurar correctivos y mejoras en beneficio de los resultados planificados; en este sentido la injerencia política constituye una amenaza a los procesos de auditoría.

La auditoría de gestión debe estar acompañada por un sistema de monitoreo y evaluación que posibilite conocer los impactos de la gestión y generar alertas oportunas para la toma de decisiones. Este sistema debe basarse en la lógica de comparar lo programado frente a lo realizado, tomando como base la planificación y la formulación realista de indicadores y metas.

Según el Gobierno Central, en su Plan del Buen Vivir, ha dicho que: en un continente desigual del mundo, el Ecuador se erige como un Estado de derechos y justicia, cuyo deber primordial es garantizar los derechos humanos. La inversión prioritaria se destina a la generación de capacidades y a la reducción de las brechas sociales y territoriales.

Para reducir la vulnerabilidad estructural de términos de intercambio que Ecuador comparte con América Latina, la inversión pública está dirigida a sembrar el petróleo y cosechar una matriz productiva para la sociedad del conocimiento. Con esto queremos decir que se priorizan proyectos de inversión que hacen más eficiente la acción del Estado y proyectos en los sectores estratégicos altamente rentables, que hacen viable la sostenibilidad del sistema económico.

Mientras el mundo desarrollado enfrenta los recortes fiscales y el aumento del desempleo que predica la ortodoxia neoliberal y que ya vivió América Latina y nuestro país, el Ecuador de la Revolución Ciudadana ejerce una política fiscal contra cíclica, que privilegia el trabajo sobre el capital, en especial en momentos de crisis.

Con una política de gobernabilidad tan ambiciosa que se encuentra implementada en el Ecuador, se ha emitido una normativa pública muy amplia, lo que aumenta el riesgo de inconsistencias y de vulnerabilidad de los sistemas, por lo tanto existe un incremento alarmante de inobservancia de los procedimientos, lo que ha enquistado actos de corrupción en casi todo el sistema público, es por esta razón la necesidad urgente de iniciar procesos de evaluación a través de auditorías de gestión en todo el Estado.

Los procesos de auditoría en América latina han ido evolucionando de forma positiva en lo que se refiere a su ejecución, es decir, las normas y procesos que deben aplicarse se han perfeccionado de tal manera que los auditores pueden realizar su tarea en apego estricto a los procedimientos establecidos, posibilitando que los auditados puedan ejercer su derecho 
a la réplica en base a justificativos igualmente establecidos en función de sus legítimos derechos.

El exceso fundamentalismo en la aplicación de los procedimientos de supervisión, ocasionalmente han condenado de forma exagerada y en otras, los culpables han sido absueltos; otro de los problemas que se puede palpar está relacionado con la posición de los auditores ante los auditados, los primeros generalmente se presentan como verdugos implacables que a costa sienten que deben encontrarle la quinta pata al gato, sí o sí, porque de no hacerlo, sentirían que su trabajo no ha cumplido con su objetivo; en otras ocasiones el auditor al encontrar delicados indicios de error o corrupción pueden ser timados o amenazados para dirimir en favor de los implicados, cayendo en el juego vergonzoso de la complicidad de hechos de repudio moral.

En los últimos años Ecuador y el mundo, han sido testigos de casos de corrupción evidente, sin que se hayan dictado medidas correctivas y sanciones ejemplarizadoras. Podríamos citar casos como el de Odebrecht, Repsol YPF, Chevron, FIFA, financiamiento de campañas políticas por parte del narcotráfico, obras cuestionables como el metro y aeropuerto de Quito; de todas estas historias se han establecido vicios de corrupción obligando a reiniciar procesos de contratación y expulsando a las multinacionales de nuestros países, sin embargo, muchos de los implicados han sido ridículamente sancionados, algunos incluso resultaron ilesos debido a su investidura de impunidad a que tienen derecho como dignatarios que no pueden ser juzgados por la justicia común, en algunas situaciones han sido sentenciados a prisión domiciliaria debido a su edad (en Ecuador mayores de 65 años) y finalmente con el tiempo, de manera milagrosa, los casos quedan en la impunidad como muchos procesos auditados relacionados con algunas autoridades elegidos por voto popular, como el caso de algunos alcaldes y asambleístas.

Quizá uno de los mayores problemas es la permanencia excesiva en la titularidad de los cargos de las instituciones de control. En Ecuador existen auditores que se encuentran fiscalizando más de veinte años e incluso el contralor general del Estado permanece en el cargo desde el 2007; personajes como esta autoridad suelen ser vistos como eminencias en el conocimiento de los procesos de evaluación, lo mismo sucede en todos los niveles jerárquicos de la Contraloría, Fiscalía, Procuraduría y en general en todas las unidades administrativas de todo el sector público.

Esta realidad obliga a fortalecer las leyes incorporando procesos más ágiles e independientes y posiblemente debería revisarse la titularidad en determinados cargos administrativos, o quizá en todos, como sucede con los jueces y comisarios.

\section{La temporalidad en la permanencia del poder de control del ejercicio de una auditoría responsable, una solución que debe considerarse en el Ecuador.}


En una sociedad ecuatoriana democrática, la permanencia en el poder se encuentra establecida por la constitución y las leyes, a través del voto popular; es así que un nuevo Gobierno debe enfrentarse a modificaciones implementadas en el sistema, instaurado por los gobernantes salientes, para lo cual debe nombrarse a nuevas autoridades que velen por el cumplimiento de lo instaurando procurando una mejora continua, el nombramiento de éstas nuevas autoridades principales en las diferentes secretarias y ministerios de estado se ajusta a perfiles muy exigentes, por lo que su renovación no siempre se la hace en todos los poderes, siendo un caso peculiar la permanencia del Contralor General del Estado.

Algunos cargos principales suelen ser delegados a servidores públicos que formaron parte del gobierno saliente o de otros anteriores, lo que debería ser positivo para la continuidad y consolidación de una economía, el hecho de colaborar con varios gobiernos no debe ser considerado negativo, incluso en varios sectores de la economía de un país es positivo la gerencia por parte de una misma autoridad, aunque en algunos casos claramente llamaría la atención la idoneidad de aquellos funcionarios que integran el equipo de gobiernos opuestos en sus ideologías y doctrinas (izquierdista y de derecha).

El cambio de un funcionario por otro, no tiene por qué perjudicar la continuidad de un proceso. Particularmente, la acción de evaluar la gestión de un gobierno saliente éticamente es inaplicable que un dignatario evalué sus propias acciones.

Desde el punto de vista de analizar el tiempo de permanencia en la gerencia de un cargo debe entenderse que el tiempo es un indicador utilizado para apreciar el proceso democrático de un sistema político. El respeto de los tiempos, en el desempeño de las funciones de los cargos públicos e incluso en la aplicación de las normas, es fundamental para establecer un sistema correcto y seguro en términos jurídicos, lo opuesto, en cierta forma es un indicador de decadencia.

Ciertos cargos públicos convienen tener una duración mayor que otros, para poder ejercer labores de continuidad de procesos y no atentar contra el cumplimiento de los objetivos iniciales en los que el Estado pudo haber realizado inversiones importantes. Otros cargos, como los de control, podrían ser atemporales con los gobiernos de turno, puesto que con ella se pretende que estas funciones mantengan independencia respecto a quienes los nombraron, dado que no serán coetáneos y tampoco podrán ser removidos durante su mandato. Por otro lado, desde un aspecto de configuración del propio Estado en su conjunto, éste resulta reforzado cuando adquiere estabilidad y proyección, al renovar ciertos cargos mientras otros permanecen.

Los cambios legislativos, que pretenden extender el mandato en las tareas públicas, evitando la efectividad, podrían significar la falta de cumplimiento del estado de derecho y 
atentar contra la legitimidad de los procesos, que son base de los estados democráticos. El deterioro es evidente, cuando por una parte se relajan los tiempos de mandato, que aumentan, y por otra, el nombramiento de los magistrados, por ejemplo, ya no se decide únicamente por órganos colegiados.

La predeterminación temporal, durante el ejercicio de un cargo público, supone una garantía democrática. Es un control objetivo e imprescindible que impregna todos los poderes del Estado. La temporalidad, además, debe estar unida a la competencia del órgano, puesto que ciertos actos, como los que le compete a un magistrado deben cuidadosamente ser transferidos al siguiente que lo releva, ya que podrían considerarse extemporáneos e implicaría su nulidad, por ello, la competencia automática del siguiente dignatario, nombrado con anterioridad, debe suponer la continuidad del proceso con la facultad de emitir criterios de corrección en pro de un balance y evaluación justos.

Vamos a observar el Derecho Romano Público institucional, en la Roma republicana, y así, reflexionaremos sobre lo que debe ser el tiempo en el desempeño de un empleo público, según lo publicado en la Revista internacional de derecho romano, la temporalidad de los cargos públicos en la roma republicana: motivo de reflexión, Olga Gil García, Profesora Doctora de Derecho Romano Universidad de Burgos, Octubre 2012, página 4, que dice:

La temporalidad en los cargos públicos electos es un hecho conocido en la Roma democrática más evolucionada. El tiempo está tan predefinido, que en la teoría general de las magistraturas romanas es calificado directamente como anualidad, aun cuando no siempre el magistrado permanecía un año en el cargo. Recordamos el caso del Dictator o el Magíster Equitum con una duración menor, seis meses, o con una duración mayor el Censor, dieciocho meses.

Y no sólo se predefine la duración, sino que está predeterminada en el calendario, dado que la fecha de inicio y fin del desempeño del cargo es concreta y coincide en la agenda anual. Cada magistratura tiene unos plazos fijos por cargo. Eran elegidos en julio y su entrada en funciones era el 1 de enero para Cónsules y Pretores, el 5 de diciembre para Cuestores, y el 10 del mismo mes para los Tribunos de la Plebe. Esta característica es tan objetiva y fija, que incluso da lugar a epónimos en el caso de los Cónsules. Por otro lado, el fin del mandato es concreto, y la consecuencia es que, una vez transcurrido el plazo prescrito, el cese es automático y el siguiente nombramiento también. Por tanto, el cargo estaba sujeto a un término certus an certus quando, y como consecuencia, no cabía ni vacío de poder, ni prórrogas de mandato.

La temporalidad incide en el derecho de igualdad de acceso de todos los ciudadanos en la función política. En la línea de lo que debe ser un derecho-deber de participar en las cosas públicas por todos, el límite temporal provoca una renovación en tales magistraturas. Ocupar cargos públicos es un privilegio, al que debe de poder acceder el ciudadano que lo pretenda, previa elección de sus conciudadanos. 


\section{Importancia de normar la relación contractual temporal para una auditoria de gestión adecuada.}

En el Ecuador, la contratación temporal ha sido implementada de manera irregular violentando el derecho al trabajo, tanto en el sector público como en el sector privado, por ello es importante normar la temporalidad exclusivamente en los cargos que realizan procesos de auditoría, nuestra historia nos revela una serie de cambios a la administración del talento humano, efectuados al margen del derecho ciudadano de contar con un trabajo permanente y más bien, cambios implementados por presión política en complicidad de dirigentes gremiales y sectores económicos poderosos.

La temporalidad en los procesos de auditoría de gestión deben observar las normas de auditoría, procurando incluir mejoras en la legislación aplicable para estos casos, considerando la temporalidad no solo estableciendo tiempos exactos sino además observando la responsabilidad que los auditores tienen sobre procesos ya iniciados y la etapa en que éstos se hallan, así como su vinculación con otros procesos planificados para su ejecución, en todo caso, siempre deberá establecerse el tiempo máximo de permanencia en el cargo.

Deberán fijarse políticas, como por ejemplo, el Contralor no debería tener la capacidad de reorganizar la estructura institucional ni la formulación de planes o equipos de auditoría, tampoco nombrar a representantes provinciales; la estructura institucional del ente de control debe estar a cargo de la Asamblea Constituyente, los planes deben ser aprobados por un directorio conformado por representantes de los diferentes poderes del Estado y representantes de participación ciudadana considerando los requerimientos institucionales del sector público o de cualquier sector de la sociedad, los equipos de auditoría deben ser organizados por sorteo interno público con observadores externos a la institución de control y de participación ciudadana, y, los auditores deben ser nombrados por concurso público para ejercer sus funciones de forma temporal con responsabilidad civil, administrativa y penal incluso por un período superior para el cual fueron nombrados.

\section{Conclusiones.}

- La auditoría debe ser entendida como un proceso de evaluación de hechos pasados con el propósito de establecer responsabilidades y sanciones por un lado y por otro debe fijar recomendaciones precisas y reales que en el futuro deberán implementarse obligatoriamente para alcanzar el mejor desempeño posible de la institución evaluada.

- Toda auditoría sin importar su especialidad en particular debe procurar que sus observaciones y recomendaciones se enfoquen en el logro de los objetivos institucionales en general.

- Los auditores deben mantener total independencia de los auditados, no puede permitirse que las partes evalúen hechos pasados ya que se cuestionaría los resultados, sin 
embargo, el auditor puede realizar recomendaciones a consultas sobre procedimientos que requieran asistencia de la forma en que deben ejecutarse actividades futuras.

- Para los procesos de auditoría gubernamental se deben implementar procesos de transparencia durante toda su ejecución, en donde deben intervenir como veedores, representantes ajenos a la autoridad de control, quienes deberán monitorear el cumplimiento del debido proceso. Los insumos tales como estados de cuenta, procesos de contratación y los mecanismos empleados como técnicas de muestreo deben ser puestos a consideración de los veedores. Actualmente un equipo de auditoría está integrado como mínimo por un supervisor y por un jefe de equipo, que son los únicos con acceso a esta información durante el proceso, al pertenecer los dos a la misma dependencia de la institución de control, obviamente velaran por su propia reputación. En mi investigación detecté que muchas de las observaciones iniciales, desaparecen en el informe final sin que exista documentación que la justifique, en otros casos no se explica porque no fueron auditados procesos que por su importancia, trascendencia o costo debieron ser incluidos en el examen.

- Todos los procesos de auditoría terminados, deben ser puestos a consideración de una comisión de veeduría que evalúe como se llevó a cabo la acción de control, esta evaluación deberá realizarse de forma periódica durante el ejercicio fiscal, de esta manera podrá detectarse irregularidades y no se tendrá que esperar denuncias futuras que evidencien actos de omisión por problemas de corrupción, tal como sucede actualmente en casos en donde establecer responsables muchas veces resulta imposible quedando en la impunidad.

- Se tiene que evaluar la posibilidad de que los auditores cumplan un ciclo obligatorio en sus funciones, no pueden permanecer en sus cargos indefinidamente, quizá la unidad administrativa de control de la Contraloría General del Estado deberá ser una excepción en la administración pública, en donde los servidores públicos en calidad de auditores sean separados de sus funciones, es decir, al igual que cualquier consultora externa, estos funcionarios estarán obligados y conscientes voluntariamente desde su incursión a ser removidos de sus cargos.

\section{Referencias bibliográficas.}

BENITEZ, B., LARREA, V., MOYA, M., MUÑOZ, M. J., \& PROAÑO, S. (2013). El consumo de bebidas energizantes y su incidencia en la ansiedad. Ambato: ENESS.

CentroIMA. (2003). Estadísticas de ansiedad. Obtenido de Centro de Investigaciones Médicas en Ansiedad: www.centroima.com.ar 
Cordero García , J. D., \& Pacheco Pacheco , D. H. (2010). Prevalencia de la Ansiedad, Depresión y Alcoholismo en estudiantes de Medicina. Cuenca, Azuay, Ecuador. Obtenido de http://dspace.uazuay.edu.ec/bitstream/datos/38/1/08066.pdf

INEC. (2012). Encuesta Nacional de Ingresos y Gastos en Hogares Urbanos y Rurales 2011 y 2012. Recuperado el 30 de julio de 2015, de http://www.inec.gob.ec/inec/index.php?option=com_content\&view=article\&id=615 $\% 3$ Amas-de-900-mil-ecuatorianos-consumenalcohol\&catid $=56 \% 3$ Adestacados $\&$ Itemid $=3 \&$ lang $=$ es

OMS. (2008). mhGAP Programa de Acción para Superar las Brechas en Salud Mental. Recuperado el 30 de Julio de 2015, de http://www.who.int/mental_health/mhgap/mhgap_spanish.pdf

OMS. (2015 ). Organización Mundial de la Salud . Recuperado el 30 de Julio de 2015, de http://www.who.int/features/factfiles/mental_health/es/

Otero de la Cruz, O. (Mayo de 2012). Ansiedad y Consumo de Alcohol en estudiantes Universitarios. Veracruz, Mexico. Recuperado el 27 de Agosto de 2015, de http://core.ac.uk/download/pdf/16307210.pdf

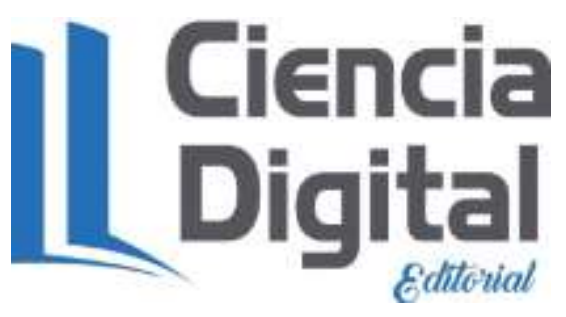




\section{Para citar el artículo indexado.}

Núñez R., Proaño E. \& Quiñónez L. (2018). Evolución de la auditoría de gestión. Revista electrónica Ciencia Digital 2(1), 361-380. Recuperado desde:

http://www.cienciadigital.org/revistascienciadigital2/index.php/CienciaDigital/article/view/ $26 / 26$

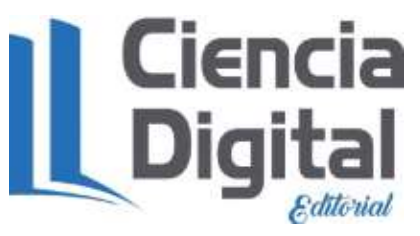

El artículo que se publica es de exclusiva responsabilidad de los autores y no necesariamente reflejan el pensamiento de la Revista Ciencia Digital.

El articulo queda en propiedad de la revista y, por tanto, su publicación parcial y/o total en otro medio tiene que ser autorizado por el director de la Revista Ciencia Digital.
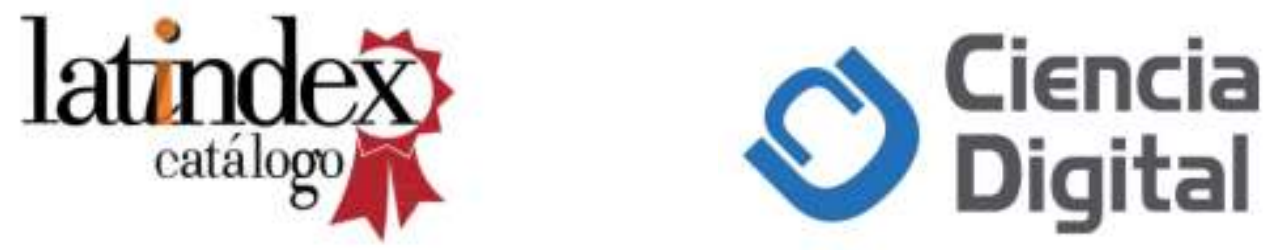